\title{
Prediction of Global Solar Radiation on the Horizontal Area with the Effect of Ambient Temperature Part: II
}

\author{
Foued Chabane ${ }^{\mathbf{1 , 2 *}}$, Zina Khadraoui ${ }^{\mathbf{1}}$, Djamel Bensahal ${ }^{3}$ \\ ${ }^{1}$ Department of Mechanical Engineering, Faculty of Technology, University of Biskra 07000, Algeria \\ ${ }^{2}$ Laboratoire de Génie Mécanique (LGM), Faculty of Technology, University of Biskra 07000, Algeria \\ ${ }^{3}$ Department of Mechanical Engineering, Faculty of Technology, University of Laghouat 03000, Algeria
}

Corresponding Author Email: fouedmeca@hotmail.fr

https://doi.org/10.18280/ti-ijes.630110

Received: 27 January 2019

Accepted: 25 March 2019

\section{Keywords:}

solar radiation, experimental study, ambient temperature, sun height, correlation.

\begin{abstract}
In the field of thermal conversion of solar energy, several studies have been conducted to model different parameters related to this process. But in all the models encountered, the parameters obtained are more or less close to reality. For us the best is the one that best reflects the variation of the modeled parameter. In fact, the confrontation of the values resulting from the experimental measurements makes it possible to judge the accuracy of the established model. In this context this study was conducted. The aim of the study is to model global solar radiation according to the ambient temperature, geographical location of the site, date and time. The obtained models are compared with the experimental results. In our experimental study we simulated the model developed by comparative study with the model of M-Y Mechraoui, showed that the experimental results are in good agreement with those given by the model developed, which is in agreement with that of $M$. Capderou,which presents a better estimate of global solar radiation with a small error between the measured values and those calculated. The set of studies was done for the Biskra site, horizontally.
\end{abstract}

\section{INTRODUCTION}

The long-term performance evaluation of solar energy conversion systems establishes through digital simulation programs. For this, according to the systems considered, the designers generally use as a time step monthly averages per day or per hour in the measure of availability. Thus, the solar radiation components required are the global irradiations incident on the sensor according to the inclination considered. This component can be accurately determined if the global components are available.

Our work consists of a first step in a bibliographic study that allows us to regroup some theoretical models established in other sites around the world. These models are in the form of empirical relationships that link the components of solar radiation to key meteorological parameters, such as ambient temperature, relative humidity, duration of insolation and astronomical parameters, such as the maximum duration of the day, the declination of the sun. sun, the variation between earth and sun and solar irradiation at the edge of the atmosphere [1].

These models can be used for single applications or for specialized users. They are based on nonlinear regressions as a function of the sun's height and the hour angle determined by correlations written according to the direct and diffuse irradiation for a horizontal plane.

Model Foued CHABANE [2], the established model based on nonlinear regressions as a function of the sun height and the relative humidity written as a function of global irradiation for several days of testing for a south-facing inclined plane $\left(45^{\circ}\right)$ :

$$
\begin{aligned}
& G_{\text {propos? }}=696.42 \times\left(\frac{h}{1.124}\right)^{1.124}+1.751 \times\left(\frac{H_{r}}{1.24}\right)^{1.24} \\
& R^{2}=0.837
\end{aligned}
$$

\section{Relationship of A.A.M.'s Sayigh [3]}

The model of Sayigh et al. Developed by means of data relating to several Indian sites, where the latitude is between $8^{\circ}$ North and $28.6^{\circ}$ North and the longitude between $72^{\circ}$ East and $88^{\circ}$ East. This relationship takes into account geographic parameters such as latitude and longitude. It also takes into account some astronomical parameters, namely, the duration of the theoretical day, the extraterrestrial irradiation calculated on a horizontal plane. The site-related meteorological parameters, which are used in this model, are: the insolation time DI, the relative humidity $\mathrm{RH}$ and the maximum temperature Tmax.

In this model, Sayighet al. have characterized climatic zones by a factor $\Psi \mathrm{i}, \mathrm{j}$. Thus according to the monthly average per day of the relative humidity and according to the month considered, they define three climatic zones respectively characterized by the ranges of the relative humidity, $\mathrm{HR} \leq 65 \%, \mathrm{HR} \geq 70 \%$ and $65 \%<\mathrm{HR}<7,0 \%$. Knowing the value of HR from the graph connecting the parameters HR and the number of the month considered, we determine the value of $\Psi \mathrm{i}, \mathrm{j}$ corresponding. However, the model of Sayighet al. Have given by the following relation:

$G_{H}=11.6 K N \exp \left(\phi\left(\frac{D I}{T_{m}}\right)-\left(\frac{H R}{15}\right)-\left(\frac{1}{T_{\max }}\right)\right)$

$N=1.7-0.458 \varphi$ 
where $\varphi$ is the latitude of the site expressed in radians.

Statistical validation of monthly mean monthly recovery models

$$
\begin{aligned}
& K=100\left(n T_{m}+\Psi_{i j} \cos (\varphi)\right) \\
& n=\frac{1}{(1+0.1 \varphi)}
\end{aligned}
$$

\section{Relationship of Reddy's [4-5]}

This relationship has also been established for several Indian sites. The same parameters used in the model of Sayighet al. Renewed in this model, but in addition Reddy took into account the number of rainy days in the month. Thus the proposed model is described by the following relation:

$$
\begin{aligned}
& G_{h}=K\left[1+0.8\left(\frac{D I}{T_{m}}\right)\right] \frac{(1-0.2 t)}{\sqrt{H R}} \\
& K=100(n t+\psi i j \cos (\varphi)) \\
& n=\frac{1}{(1+0.1 \varphi)}
\end{aligned}
$$

\section{Swartman's relationship [6]}

Similarly, with the relative data of 14 Indian stations, two relationships were established by Swartman. These relationships make it possible to estimate the global irradiation on a horizontal plane from the duration of insolation and the relative humidity. In this model, as the astronomical duration of the day, the author assumes that the latter is equal to 12 hours per day for each month of the year. These two relationships are given as follows:

$$
\begin{aligned}
& G_{h 1}=11.6 * 490\left(\frac{D I}{12}\right)(0.35 H R)^{-0.262} \\
& G_{h 2}=11.6 * 460 \exp 0.607\left(\frac{D I}{12}-H R\right)
\end{aligned}
$$

\section{- Relationship of A.S Sambo [7]}

A 60-month period of insolation duration, maximum and minimum temperatures, mean temperature and specific humidity was used to develop 12 different correlations with which the monthly average per day of irradiation overall can be calculated for the Kano site in northern Nigeria.

The correlations obtained were combined to arrive at a simplified type of Angstrom equation, this correlation is given as follows:

$$
\begin{aligned}
K_{T}= & 0.62-0.294 \frac{D I}{T_{m}}+0.178\left(\frac{D I}{T_{m}}-H R-\frac{T_{\min }}{T_{\max }}\right)+ \\
& 0.491\left(\frac{D I}{T_{m}} * \frac{T_{\min }}{T_{\max }}\right)
\end{aligned}
$$

Relationships of Sabbagh et al. [8]

Based on data for several Gulf countries, in particular, Saudi Arabia sites, Sabbaghet al. have developed two empirical relationships linking the different meteorological parameters that affect the attenuation of solar radiation, namely: the duration of insolation DI, the relative humidity $\mathrm{RH}$, the maximum temperature Tmax, the altitude $\mathrm{Z}$, the geographical situation (longitude The latitude $\varphi$ and its location with respect to the sea and a water lake characterized by the characteristic area factor, which are given by the following relationships:

$$
\begin{aligned}
& G_{h}=18.1 K \exp \left[\varphi\left(\frac{D I}{12}\right)-\left(\frac{H R}{100}\right)^{1 / 3}-\left(\frac{1}{T_{\max }}\right)\right] \\
& G_{h}=18.4(419.391 D I-292.73 H R+330.571)
\end{aligned}
$$

Model Michraoui Mohamed-Yazid [9], The established model was based on nonlinear regression as a function of sun height written as a function of global irradiation for several days of testing for a horizontal plane and other south-facing inclined plane.

The global radiation as a function of the height of the sun can be written in the form from the experimental measurements, one calculates according to the shape of the model chosen (Exponential Exp3P2), the coefficient A and the exponent $\mathrm{B}$ and $\mathrm{C}$. This gives us the week model in the form:

$$
G_{\beta}=\exp \left(A+B \times h+C \times h^{2}\right)
$$

Capderou model [10], uses the atmospheric disturbance coefficient to calculate the direct and diffuse components of irradiation received on a plane. The absorption and diffusion caused by the constituents of the atmosphere can be expressed by factors of disorders. From these factors, it is possible to express direct and diffuse light sky irradiation.

\section{EXPERIMENTAL AND THEORETICAL STUDY}

Several studies have been conducted to model solar radiation, but in all models encountered, the parameters obtained are more or less close to the truth. For us the best is the one that best developed the variation of the modeled parameter. In fact, the measurement of gate values and the experimental measures allow us to judge the legality of the established model. In this context this study was conducted. The aim of the study is to model global solar radiation according to humidity, date and time. The obtained models are compared with the experimental results.

\subsection{Biskra city feature}

Currently, in Algeria, the measurement of solar radiation data is carried out instantly and only at certain sites in Algeria. The city of Biskra is characterized by its Saharan climate is located at a latitude of $34^{\circ} 48^{\prime}$ nord and a longitude of $5^{\circ} 44^{\prime}$ Est, its altitude compared to the sea level is $87 \mathrm{~m}$. This region is treated by a dry climate in summer. The tests are done for clear days.

\subsection{Instrumentation}

The measurement campaign was carried out in the Technological Hall of the Department of Mechanical Engineering at the University of Biskra. 


\section{-Pyranométre:}

The Pyranometer is a heat flux sensor used to measure global solar radiation (the amount of solar energy in natural light), it is manufactured on the basis of thermal photoreceptor. It allows the measurement of the power of total solar radiation in watts per square meter. It is sensitive in a spectral range of 300 to 2500 nanometers, depending on the filter used.

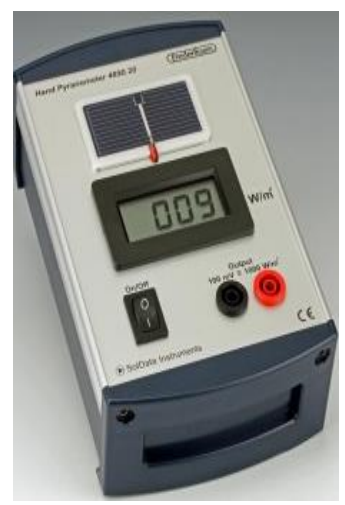

Figure 1. Pyranometer

\section{- Hygrometer:}

This hygrometer is designed to quickly measure the temperature and humidity of the air. The hygrometer gives you additional information, such as the dew point (dew point temperature) as well as the temperature of the wet bulb.

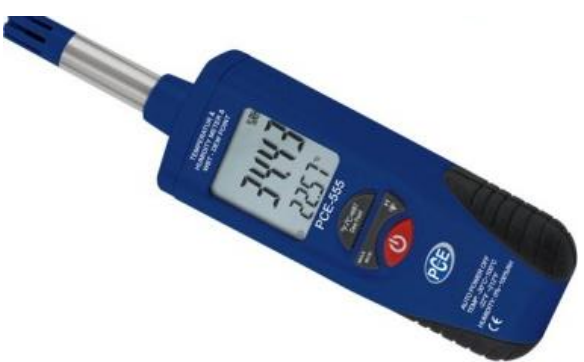

Figure 2. Hygrometer

\subsection{Theoretical study}

The established model is based on non-linear regressions as a function of relative humidity and sun height written according to the overall irradiation for several days of testing for a horizontal plane. The global solar radiation can be written in the form of From the experimental measurements, we calculate according to the shape of the chosen model: Power. This gives us the model proposed in the form:

$G_{\text {propos閏 }}=A \times\left|\left(h+\frac{T_{a}}{320}\right)-X_{C}\right|^{P}$

According to measurements made at the University of Biskra, we sort the results obtained from January to April of 2018.

We try to obtain the relative humidity and the global solar radiation on the horizontal plane correspond to the true solar time and the sun height, see the tables below:
Table 1. The values of the coefficients $\mathrm{A}, \mathrm{X}_{\mathrm{C}}$ and $\mathrm{P}$ of model according to the months

\begin{tabular}{|c|c|c|c|}
\hline Month & A & Xc & p \\
\hline 1 & 0,0000405 & $-42,91$ & 3,7 \\
\hline 2 & 0,00438 & $-32,28$ & 2,71 \\
\hline 3 & 0,00393 & $-44,136$ & 2,772 \\
\hline 4 & 0,016 & $-59,066$ & 2,423 \\
\hline 5 & 0,2623 & $-35,379$ & 1,835 \\
\hline 6 & 0,724 & $-21,844$ & 1,594 \\
\hline 7 & 0,3221 & $-32,258$ & 1,771 \\
\hline 8 & 0,02707 & $-45,4$ & 2,334 \\
\hline 9 & $5,792 \mathrm{E}-16$ & $-153,593$ & 7,999 \\
\hline 10 & 0,009 & $-31,669$ & 2,546 \\
\hline 11 & $3,472 \mathrm{E}-08$ & $-71,725$ & 4,741 \\
\hline 12 & 0,00203 & $-21,009$ & 2,813 \\
\hline
\end{tabular}

Experimental scientific methods consist in testing by repeated experiments the validity of a hypothesis. Obtaining new qualitative or quantitative data confirms or invalidates the initial hypothesis. The scientific experiment differs from other experiments in that it requires, to be credible, the application of an experimentation protocol that makes it possible to accurately reproduce a particular experiment. Measuring instruments are also used as reference instruments because of their high measurement accuracy. The use of these sensors is crucial for measurements in meteorological applications.

\section{RESULTS AND DISCUSSION}

There are several models for the simulation of global solar irradiance, expressed by semi-empirical approaches. In the field of thermal conversion of solar energy, several studies have been conducted to model this parameter. But in all the models encountered, the values obtained are more or less close to reality. For us, the best is the one that best reflects the variation of the modeled parameter. In fact, the confrontation of the values resulting from the experimental measurements makes it possible to judge the accuracy of the established model. In this context the following comparison was conducted. It therefore consists in comparing the model established, based on the tests carried out over a specific period of time and that given by Capderou. The whole is confronted with the experimental results.

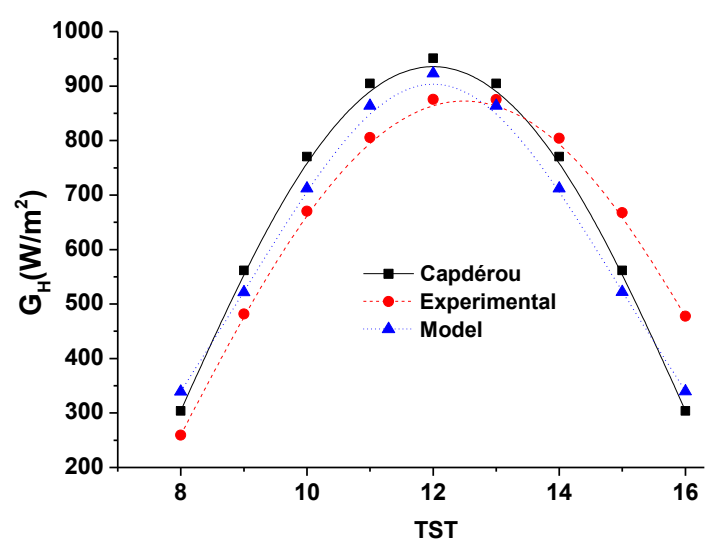

Figure 3. Comparison: The evolution of global solar radiation "Models proposed - Measure 2018 - Capderou 


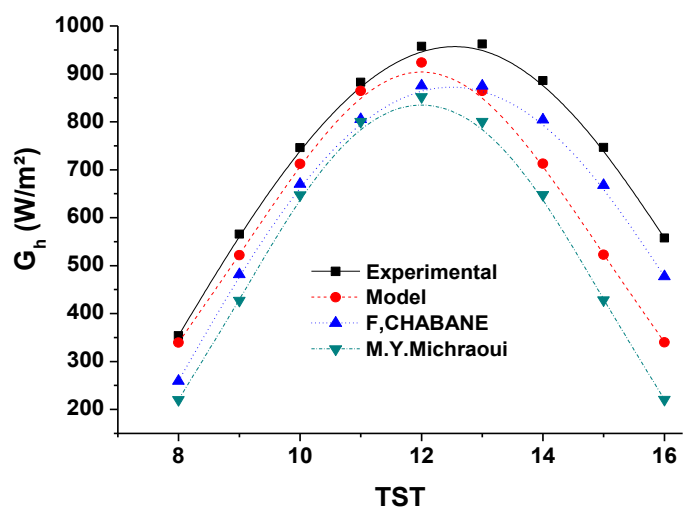

Figure 4. Comparison: The evolution of global solar radiation "Proposedmodels-Measure 2018- F.Chabane-MY.Mechraoui" following the month of April

The above figures show comparative graphs of the global radiation of the models simulated with the experimental data collected and the semi empirical model of Capderou in the considered site. For this purpose, the representative curves of the measured values and those estimated by each of the models were first drawn up on the same curve.

For the Capderou model and the model established, we note that for most situations, the values of the global component estimated are very close to the measured values. The average relative error is small.

The figures above, represent the variation of the global solar radiation on the horizontal plane according to the true solar time in the site of Biskra according to the months of March, May and June. The following evolution of the three cases such as the Capderou model, the established model and the measured data of the global solar radiation 2018. We notice that the variation of the two models of the global solar radiation is more approach according to the measured data, thus the modeled ones. they give good agreement with the measured values 2018 see Figure 4.

This step is devoted to the theoretical and experimental aspect, will be followed by an instantaneous average relative error calculation on global solar radiation. The calculation of relative error will be put in place to judge the reliability of the model proposed at our site.

The expression of the latter is given by the following equation:

$E r r=\left|\left(\frac{G_{\text {mod }}-G_{\text {exp }}}{G_{\mathrm{mod}}}\right)\right| \times 100$

Figure 5 shows the relative error between the experimental data and the proposed model data, according to the winter season. Note that the relative error takes maximum values in January against February and December which reach the value $37.5 \%$.

For the spring season recorded the maximum error for the month of April which is approaching the value $35 \%$. See Figure 6.

The summer season showed the maximum error relative to the month of July but minimum values against the months president who reached $19.5 \%$. See Figure 7 .

Finally, the fall season we note the maximum value in November is $42.5 \%$. See Figure 8 .

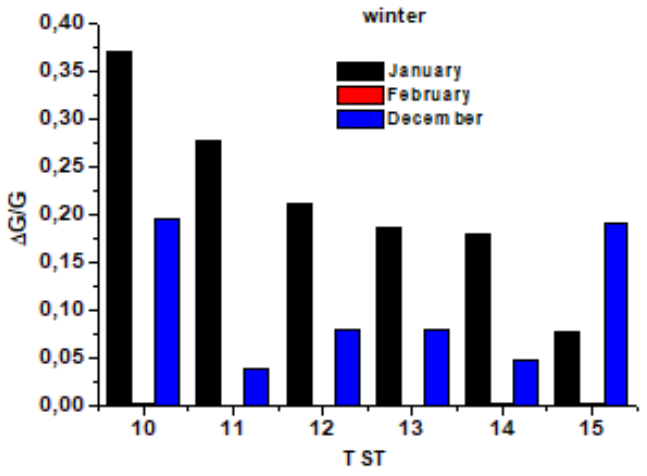

Figure 5. Mean relative error between the experimental values of the global radiation and the proposed model according to the winter months

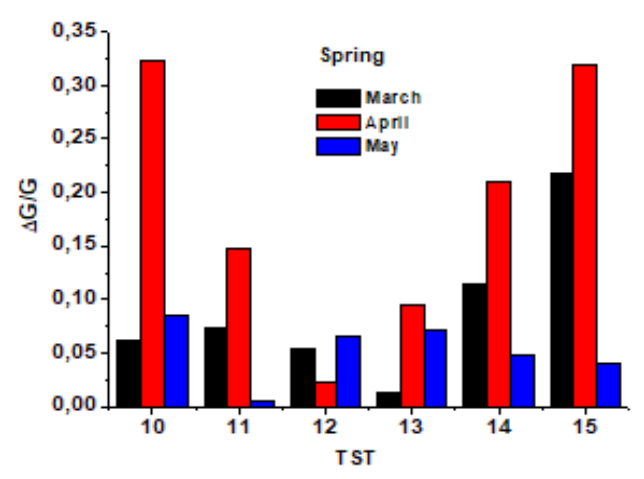

Figure 6. Mean relative error between the experimental values of the global radiation and the proposed model according to the spring months

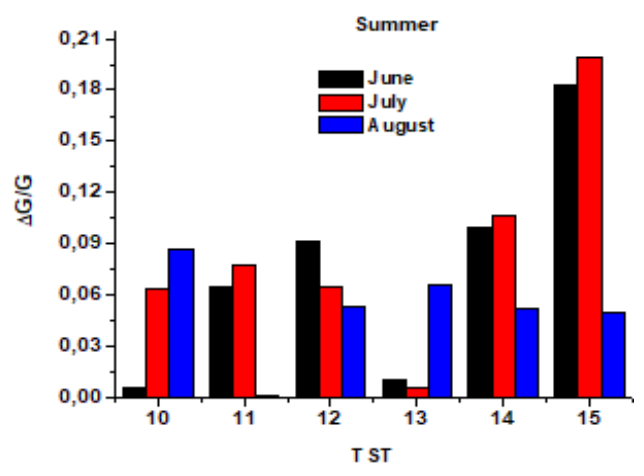

Figure 7. Mean relative error between the experimental values of the global radiation and the proposed model according to the summer months

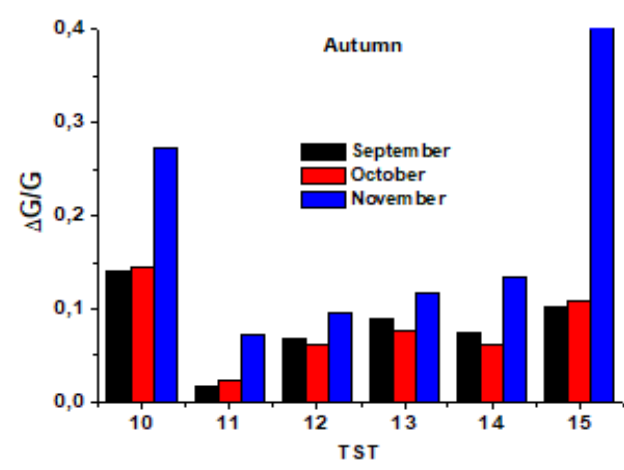

Figure 8. Mean relative error between the experimental values of the global radiation and the proposed model according to the autumn months 


\section{CONCLUSIONS}

This work is done to propose a model sufficient to predict in different contexts of global solar radiation on a horizontal plane. This is very important for a whole series of applications of solar energy conversion. Indeed, the lack of data before, we will not know what will be the previous solar potential to ensure such a feasibility or such function.

The work encountered, which is analyzed in the literature relating to the modeling of solar radiation, shows a variety of models. There are those based on experimental data specific to the sites studied and then those based on simulation. But for each case the model can be improved or questioned; its place and area of validity can be clearly seen.

After this study, the development of a suitable model for the Biskra site for a horizontal plan, of any solar project was made through an experimental study. The experimental results show that the values found give a good estimate of the solar radiation and are in good agreement with those given by the elaborate model which is in agreement with that of Capderou.

In perspective, we hope that the next promotions will use our results as a database that will serve as a reference for studies in the solar field.

Data processing is performed on selected measures covering the year 2016, collected every hour for the Biskra site. All these steps make it possible to choose adequate models from these studies which has the values found are in good agreement with those given by the model developed which is in agreement with that M.Capderou. Also note that the model are very close to the experimental.

According to the confrontations and the results obtained, we have judged that: the evolution of global solar radiation on the horizontal plane induced by the proposed model is close to that measured during the experiment, as it is close to the work done by Dr. Chabane and MYMechraoui.

\section{REFERENCES}

[1] Koussa M, Haddadi M, Malek A. (2007). Reconstitution des irradiations globale et diffuse en fonction de quelques paramètres météorologiques pour un ciel quelconque. Revue des Energies Renouvelables. 10.

[2] Chabane F. (2015). Modélisation des paramètres de la conversion thermique de l'énergie solaire. thèse doctorat en sciences en Génie Mécanique 2015.

[3] Sayigh AAM. (1977). Solar Energy Engineering. Academic Press, INC (London) LTD.

[4] Boldbeg B, Klein WH, McCartney RD. (1979). A comparison of some samples used to predict solar irradiance on a horizontal surface. Solar Energy 23(1): 81-83. https://doi.org/10.1016/0038-092X(79)90047-1

[5] Reddy SJ. (1971). An empirical method for the estimation of total solar radiation. Solar Energy 13(2): 289-290. https://doi.org/10.1016/0038-092X(71)900107

[6] Swartman RK, Ogunlade O. (1967). A statistical relationship between solar radiation, sunshine and relative humidity in the tropics. Atmosphere 5(2): 25-34 https://doi.org/10.1080/00046973.1967.9676534

[7] Sambo AS. (1986). Empirical models for the correlation of global solar radiation with meteorological data for the Northern Nigeria. Solar Energy 3(2): 89-93. https://doi.org/10.1016/0741-983X(86)90019-6

[8] Sabbagh JA, Sayigh AAM, El Salam EMA. (1977). Estimation of the total solar radiation from meteorological data. Solar Energy 19(3): 307-311. https://doi.org/10.1016/0038-092X(77)90075-5

[9] Mohamed-Yazid Mechraoui (2017). Etude comparative de deux modelés de calcul du rayonnement solaire par ciel claire en Biskra. Master thesis, University of Biskra.

[10] Capderou M. (1985). Atlas solaire de l'Algérie. O.P.U., Alger. 